\title{
UNIVERSITYOF
}

FORWARD

THINKING

WESTMINSTER用

WestminsterResearch

http://www.westminster.ac.uk/westminsterresearch

The effect of playground and nature-based interventions on physical activity and self-esteem in UK school children

Barton, J., Sandercock, G., Pretty, J. and Wood, C.

This is an author's accepted manuscript of an article published by Taylor \& Francis in the International Journal of Environmental Health Research 25 (2) 196-206, 2014. The final definitive version is available online at:

https://dx.doi.org/10.1080/09603123.2014.915020

The WestminsterResearch online digital archive at the University of Westminster aims to make the research output of the University available to a wider audience. Copyright and Moral Rights remain with the authors and/or copyright owners.

Whilst further distribution of specific materials from within this archive is forbidden, you may freely distribute the URL of WestminsterResearch: ((http://westminsterresearch.wmin.ac.uk/)).

In case of abuse or copyright appearing without permission e-mail repository@westminster.ac.uk 
The effect of playground- and nature- based playtime interventions on physical activity and self-esteem in UK school children

Barton J, Sandercock G, Pretty J, and Wood C*.

School of Biological Sciences, University of Essex, Colchester, United Kingdom

*Corresponding Author: School of Biological Sciences, University of Essex, Colchester, CO43SQ, United Kingdom. Email: cjwood@essex.ac.uk 


\section{The effect of playground- and nature- based playtime interventions on physical activity and self-esteem in UK school children}

School playtime provides opportunities for children to engage in physical activity (PA). Playtime interventions can increase PA; however there is disparity between results. Nature can also promote PA, the purpose of this study is to determine which interventions are most effective at increasing moderate-vigorous PA (MVPA) and if this varies by school location. Fifty-two children from an urban and rural school participated in a playground sports (PS) and orienteering intervention during playtime. PA was assessed the day before and on the final day of the interventions using accelerometers. Intervention type $(\mathrm{P}<0.05)$ and school location $(\mathrm{P}<0.001)$ significantly influenced MVPA; with PS increasing MVPA more than orienteering and urban children responding more positively. There was a positive correlation for fitness and MVPA during $\mathrm{PS}(\mathrm{r}=0.32 ; \mathrm{P}<0.05)$, but not orienteering $(\mathrm{P}>0.05)$. The provision of PS influences PA the most, however a variety of interventions are required to engage less fit children in PA.

Keywords: Physical activity; playtime, urban, rural, nature

\section{Introduction}

Many UK school children aged 5-10 years (26-34\%) do not perform the recommended daily 60 minutes of moderate to vigorous physical activity (MVPA) (NHS Information Centre 2010). Regular physical activity (PA) during childhood is essential for good physical and psychological health (PH) (Department of Health 2011). In common with the adult data, a meta-analysis of paediatric exercise interventions shows a similar, moderate effect size for changes in children's self-esteem (SE) due to exercise (Ekeland et al 2004). However, opportunities for children to be active are diminishing and children follow an increasingly sedentary way of life (Biddle et al 2004). Time spent outdoors is a positive correlate of PA (Cleland et al 2008), yet children spend less time outdoors than previous generations due to safety concerns, traffic and parental fear of crime (Bird 2007). Children are also drawn inside 
by the attraction of indoor alternatives such as TV and computer games (Biddle et al 2004). Children of a lower socio-economic status (SES) are a group of particular concern, as they have greater access to sedentary activities but reduced access to portable play equipment such as bicycles; which facilitate PA (Tandon et al 2012).

School playtime provides an ideal opportunity to promote PA in an outdoor environment (Ridgers et al 2006). Children receive up to 55 minutes of school playtime each day, equating to 183 hours per year. If all this time were used for PA, playtime would provide $50 \%$ of the total amount required (Ridgers et al 2006, 2007a). However, playtime currently only contributes $5-40 \%$ towards the daily activity requirement (Ridgers et al 2006). There is large variation in the calculated contribution of school playtime due to differences in PA assessment methods, the countries in which the studies were performed and playtime durations.

Playtime interventions such as equipment provision and playground markings have successfully increased time spent in MVPA during school playtime by up to 60\% (Stratton 2000; Stratton and Mullan 2005; Verstraete et al 2006; Ridgers et al 2007b; Haug et al 2010). However, some studies also suggest that playtime interventions do not significantly influence PA levels (Ridgers et al 2007a; Haug et al 2010; Ridgers et al 2010). The sustainability of increases in PA over time is also questionable as short-term changes may be due to novelty effects of the interventions (Ridgers et al 2006; Stratton 2000). The location of playtime interventions may also impact upon their effectiveness. Natural environments provide large open spaces for activity and can create more imaginative and inventive play than urban environments lacking nature (Bird 2007). Individuals with access to nature are three times as likely to be active (Wells et al 2007) and natural settings can improve concentration, cognitive function and social play (Wells 2000). In adults, performing PA whilst exposed to nature ("green exercise") provides additive benefits for psychological health, largely through 
improvements in SE (Pretty et al 2005; Barton and Pretty 2010). However, there is a paucity of green exercise studies in children and those simulating the experience using nature images have shown no additive benefit to self-esteem (Wood et al 2012).

The school environment may provide a vital opportunity for children to have contact with nature. Accessing green space and engaging in outdoor play during the school day is therefore a key component to the health, wellbeing and development of children (Ward Thompson et al 2008). Yet, children spend much of their playtime in the playground (Ridgers et al 2006) and often have limited access to green spaces within the school environment. The primary purpose of this study was to determine which type of playtime intervention is most effective at increasing PA levels and improving SE in UK school children. A secondary aim was to compare the effect of the interventions in children attending schools located in urban and rural settings.

\section{Methodology}

\subsection{Participants}

Fifty two boys and girls aged $8.84 \pm 0.45$ years $($ mean \pm SD) volunteered to participate in the study. Participants were recruited from two primary schools located in socially-deprived urban and rural areas in England (Colchester Borough Council 2004). The two areas were in the $20 \%$ most deprived in England for one or a combination of factors including barriers to housing, income and health deprivation, crime, and living environment deprivation (Colchester Borough Council 2004). The participants in each school were derived from a year 5 class; the sample size was determined by the relative size of each class. Informed parental and individual consent were obtained for each child prior to the start of the study. Only children who returned consent forms participated. Institutional faculty ethical approval was granted for the study. 


\subsection{Procedure}

At the start of the project participants' stature was measured with the participant barefoot and to the nearest $0.1 \mathrm{~cm}$ (Seca 220 stadiometer) and mass measured to the nearest $0.1 \mathrm{~kg}$ (Seca 770 digital scale). Body mass index (BMI) and BMI z-scores (Cole et al 1995) related to the individuals' age and sex were also calculated. Cardio respiratory fitness was determined using the $20 \mathrm{~m}$ shuttle run test (20mSRT) (Leger et al 1988). The 20mSRT required participants to run between markers, $20 \mathrm{~m}$ apart, in time to pre-recorded beeps. The initial running velocity was $8.5 \mathrm{~km} \cdot \mathrm{h}^{-1}$, increasing by $0.5 \mathrm{~km} \cdot \mathrm{h}^{-1}$ each minute. The test was terminated due to volitional fatigue or when the participant failed to reach the marker at the beep on two consecutive occasions (Leger et al 1988). The number of shuttles each participant completed was recorded and converted to running speed $\left(\mathrm{km} \cdot \mathrm{h}^{-1}\right)$. 20mSRT Zscores were then calculated from age and sex-related normative data (Olds et al 2006). A positive or negative z-score indicates an above or below average score respectively.

Two playtime interventions were then introduced into each of the schools during lunch playtime for one week between November and December 2009. The interventions were available for the whole fifty five minute duration of lunch playtime on five consecutive days. The weather did not prevent the children from accessing either of the interventions on any of the five days. A playground sports (PS) equipment intervention was implemented followed by an orienteering intervention. The order was requested by the school due to circumstances out of our control. The PS intervention was performed on the playground and consisted of small pieces of equipment such as skipping ropes, bats and balls and Frisbees. The orienteering intervention was carried out on the school field and green areas surrounding the school buildings. Children were provided with a map of the school grounds and a course with markers to follow and the course was altered on each day of the intervention. The dimensions 
of the green and playground areas were comparable and all children participated fully in both interventions.

\subsection{Instrumentation}

PA levels were monitored for one day prior to the start of the intervention and on the final day of each intervention using accelerometers (Actigraph GT1M, MTI Health Services Inc.). Activity levels were monitored during the 55 minute lunch break using a $1 \mathrm{~s}$ epoch. Accelerometers were worn on a belt, over clothing, positioned on the right hip. Accelerometer data were downloaded using the Actilife programme (v4.4.1) and processed using ActiSci V0.99b5. The time spent in MVPA was determined using established cut points (Trueth et al 2004), with an adjustment made for the accelerometer model (Corder et al 2007).

SE monitoring took place immediately after lunch break, the day before each intervention and again at the same time on the final day of the intervention. SE was assessed using the one-page 10-item Rosenberg Self-esteem scale (Rosenberg 1965); the instruments test-retest correlations range from 0.82-0.99 and reported cronbach's alpha coefficients range from 0.77-0.88 (Blascovich and Tomaka 1991). The scale was slightly modified to ensure the language could be understood by the age-group of children involved. For example, participants are normally asked how they feel about themselves and whether they strongly agree, agree, disagree or strongly disagree with a list of 10 statements. This was amended to whether the participants thought the statements to be very true, true, not true or definitely not true. Some statements were also modified to make them more comprehensible in terms of language, for example "I am able to do things as well as most other people" was changed to "I can do things as well as most other children". 


\subsection{Data Analysis}

Two-way between ANOVA examined differences in anthropometric and fitness data according to sex and school location. Two-way mixed ANCOVA examined the changes in time spent in MVPA according to the intervention type and school location, with the preintervention MVPA, BMI z-score and 20mSRT z-score being included in the analysis as covariates. Pearson's correlation examined the relationship between fitness and the change in MVPA following the orienteering and PS interventions separately. Two-way ANCOVA also examined the effect of the intervention type and school location on the change in SE, with pre- intervention SE scores, BMI z-score and 20mSRT z-scores being included in the analysis as covariates. Significance was accepted as $\mathrm{P}<0.05$ throughout the analysis.

\section{Results}

Two way between ANOVA revealed a significant difference between urban and rural school children in age $(\mathrm{F}(1)=4.75 ; \mathrm{P}<0.05)$, stature $(\mathrm{F}(1)=9.17 ; \mathrm{P}<0.01), \mathrm{BMI}(\mathrm{F}(1)=14.04 ; \mathrm{P}<0.001)$ and BMI Z-score $(\mathrm{F}(1)=14.47 ; \mathrm{P}<0.001)$. Participants in the rural school were older and taller, but had a lower BMI and BMI Z-score than the urban school children. There were no differences $(\mathrm{P}>0.05)$ between mass, 20mSRT speed or 20mSRT $\mathrm{z}$-score in the urban and rural schools (Table I). ANOVA also revealed significant sex differences in age $(F(1)=4.21$; $\mathrm{P}<0.05)$ and $20 \mathrm{mSRT}$ speed $(\mathrm{F}(1)=19.54 ; \mathrm{P}<0.001)$ for all children combined. Females were younger and reached a slower final speed on the $20 \mathrm{mSRT}$. There were no sex differences in stature, mass, BMI, BMI z-score or $20 \mathrm{mSRT}$ z-score $(\mathrm{P}>0.05)$. There were no significant effects for any of the variables due to the interaction of the school location and sex $(\mathrm{P}>0.05)$.

Descriptive data according to school location and activity type is reported in Table II. Two-way ANCOVA showed a significant main effect for the change in the time spent in MVPA due to the intervention type $(\mathrm{F}(1)=5.78 ; \mathrm{P}<0.05)$ and school location $(\mathrm{F}(1)=23.42$; 
$\mathrm{P}<0.001)$, but no interaction effect $(\mathrm{P}>0.05)$. The PS intervention increased the time spent in MVPA more than the orienteering intervention and the urban school increased their time spent in MVPA to a greater extent than the rural school (Table III). ANCOVA also revealed that there was a significant effect of pre-intervention time spent in MVPA on the change in the time spent in MVPA $(\mathrm{F}(1)=18.97 ; \mathrm{P}<0.001)$ and also a significant effect of the $\mathrm{BMI} \mathrm{Z}$ score on the change in the time spent in MVPA $(\mathrm{F}(1)=6.85 ; \mathrm{P}<0.05)$. There was no effect of the 20mSRT z-score on time spent in MVPA.

Pearson's correlation revealed a positive correlation for children of all fitness, determined by the maximum speed achieved on the 20mSRT, and time spent in MVPA during the PS intervention $(\mathrm{r}=0.32 ; \mathrm{P}<0.05)$, but not during the orienteering intervention $(\mathrm{P}>0.05)$.

Two-way ANCOVA revealed no significant main effects on SE, due to either the type of intervention $(\mathrm{P}>0.05)$, school location $(\mathrm{P}>0.05)$ or interaction of both variables $(\mathrm{P}>0.05)$ (Table IV). The pre- intervention SE score significantly affected the post- intervention SE score $(\mathrm{F}(1)=25.09 ; \mathrm{P}<0.001)$. There was no effect of BMI Z-score or $20 \mathrm{mSRT} \mathrm{z}$-score on post- intervention SE ( $\mathrm{P}>0.05)$.

\section{Discussion}

This primary aim of this study was to determine which type of playtime intervention is most effective at increasing PA levels and improving SE in UK school children. The results indicated that the PS intervention led to significantly greater increases in the time spent in MVPA compared to the orienteering intervention, irrespective of the school location. The time spent in MVPA following the PS intervention contributed $21 \%$ towards the daily PA recommendation; whilst the time spent in MVPA following orienteering only contributed 13.7\%. Previous studies support the finding that the provision of games equipment during playtime leads to increases in PA (Verstraete et al 2006; Haug et al 2010). However, no 
studies to date have documented the effects of a nature-based intervention on PA. Greater increases in PA might have been expected following the orienteering intervention; as access to nature has been associated with increased levels of PA (Wells et al 2007). On the other hand, the PS intervention may have encouraged more vigorous activity than the orienteering, as orienteering requires cognitive thinking which may influence PA levels.

There was a positive relationship between fitness and time spent in MVPA for the PS intervention, suggesting that fitter children chose to engage more with the sports equipment than less fit children. There was no correlation between fitness and time spent in MVPA during the orienteering, indicating that this type of intervention may be effective at engaging children of all fitness levels. PA in man-made settings is based on a hierarchy of physical strength and skill (Bird 2007), whereby the fittest and most able individuals dominate. Natural areas stimulate more diverse and creative play, providing opportunities for children of all abilities to take part (Bird 2007). The orienteering intervention was more inclusive than the PS intervention; thus nature-based interventions should be used as a tool to engage children of all abilities in PA during school playtime.

Both the PS and orienteering interventions led to improvements in SE, however there were no significant differences in the change in SE due to the type of intervention. In adults, performing PA whilst exposed to nature has been demonstrated to provide synergistic benefits for psychological health (PH) (Pretty et al 2005; Barton and Pretty 2010; Pretty et al 2007). In children there is no additive benefit of nature-based interventions for SE, above that provided by playground-based interventions. The current generation of children spend significantly less time interacting with nature than previous generations (Bird 2007). As such, it is possible that they have become disconnected from the natural environment in a way that limits them from receiving benefits for PH (Bratman et al 2012). However, the effects of the nature-based intervention may have been limited by the duration of the orienteering, the type 
of activity and factors such as weather and temperature. Further investigation into the benefits of green exercise and activity requiring interaction with nature is warranted in children.

The secondary aim of this study was to compare the effect of the interventions in children whose schools were located in either an urban or rural setting. Environmental location may affect health risk factors. In this study, children attending the urban school had a significantly higher BMI (and BMI z-score) than those from the rural school and were more likely to be classified as either overweight or obese. SES may affect BMI, due to limited opportunities for PA and greater access to sedentary activities in more deprived individuals (Tandon et al 2012). Whilst both of the schools within this study were within areas which were in the $20 \%$ most deprived in England, they were categorised as deprived for different reasons. The urban school was in an area deprived in terms of education, skills and training, income, crime and employment, whilst the rural school was only deprived in terms of housing and access to key services (Colchester Borough Council 2004). Poor income and a lack of employment are likely to prevent individuals from having bicycles or portable exercise equipment (Tandon et al 2012), whilst having to travel to reach key services such as a supermarket or doctor is not.

In terms of MVPA, the urban school children responded to the interventions more positively than the rural school children. Whilst the urban children experienced increases in MVPA by $4.2 \mathrm{~min}$ and $4.6 \mathrm{~min}$ due to the PS and orienteering interventions respectively, the rural children only experienced $1.9 \mathrm{~min}$ and $0.2 \mathrm{~min}$ increases respectively. The urban children may have responded more positively to the playground intervention, as they may not have access to the equipment outside of the school environment. Furthermore, children living in a deprived urban area are less likely to have regular access to nature (Bird 2007). The interventions provided new and exciting opportunities for the urban children, but may have been more familiar to the rural children, thus leading to the disparities in their effects. The 
findings suggest a need for bespoke activity interventions informed by the school location, characteristics and fitness levels of the children.

The urban children experienced slightly greater improvements in SE following the playtime interventions; however these differences were non significant. The urban children performed more MVPA during the interventions and seemed to engage with the interventions to a greater extent than the rural children; thus the slightly more positive changes in SE might have been expected. Urban residing children also have less frequent opportunities for day-today contact with nature than rural children (Bird 2007), perhaps providing some explanation as to why they experienced a more positive enhancement in SE following orienteering. To date this is the first known study to examine the effect of different playtime interventions on SE and to compare the effects in urban and rural school children.

The present study has several limitations. Firstly, the lack of randomisation of the interventions may have impacted upon the results. Randomisation helps to control for the potential novelty effects of the interventions and prevents one intervention from impacting upon the other. Since the playground intervention was performed first and there was only a one week gap between the interventions, the playground intervention may have directly impacted upon the pre-orienteering MVPA. The timings of MVPA assessment postintervention may also be considered as a limitation, as only one day of monitoring took place. Additional monitoring would provide a more thorough assessment of the impact of the interventions on PA.

\section{Conclusion}

This study indicates that whilst both nature- and playground- based interventions can increase the time spent in MVPA during playtime, the more traditional playground interventions are more effective at increasing PA and urban children seem to respond more positively to 
playtime interventions than rural children. Children with lower fitness tend to be disengaged with the more traditional playground activities; thus nature-based interventions may provide vital opportunities for PA in these groups of children. Playtime interventions can also promote improvements in SE; however these do not significantly vary according to the type of intervention or the location of the school. This study demonstrates that it is essential that a multi-faceted approach be utilised in order to engage children in PA during school playtime, whilst also taking advantage of the numerous health benefits derived from playing in all areas of the school grounds. Nature-based interventions should be implemented alongside playground-based interventions to provide opportunities for children of all abilities to engage in PA during playtime. 


\section{References}

Barton J, Pretty J. 2010. What is the best dose of nature and green exercise for improving mental health? A multi-study analysis. Environ Sci Technol. 44: 3947-55.

Biddle S, Gorely T, Stensel D. 2004. Health-enhancing physical activity and sedentary behaviour in children and adolescents. J Sports Sci. 22:679-701.

Bird W. 2007. Natural Thinking: Investigating the Links between the Natural Environment, Biodiversity and Mental Health. Reading: Royal Society for the Protection of Birds,

Blascovich J, Tomaka J. 1991. Measures of self-esteem. In: Robinson J, Shaver P, Wrightsman L, (editors). Measures of personality and social psychological attitudes, Vol. I. San Diego, CA: Academic Press.

Bratman GN, Hamilton JP, Daily GC. 2012. The impacts of nature experience on human cognitive function and mental health. Ann N Y Acad Sci. 1249:118-36.

Cleland V, Crawford D, Baur LA, Hume C, Timperio A, Salmon J. 2008. A prospective examination of children's time spent outdoors, objectively measured physical activity and overweight. Int J Obes. 32:1685-93.

Colchester Borough Council. 2004. The English Indices of Deprivation for Colchester. Revised 2004. Geographical Analysis for Colchester. London: Office of the Deputy Primeminister.

Cole T, Freeman J, Preece M. 1995. Body mass index reference curves for the UK, 1990. Arch Dis Child. 73:25-9. 
Corder K, Brage S, Ramachandran A, Snehalatha C, Wareham N, Ekelund U. 2007. Comparison of two Actigraph models for assessing free-living physical activity in Indian adolescents. J Sport Sci. 25:1607-11.

Department of Health. 2011. Start active, stay active: a report on physical activity from the four home countries' Chief Medical Officers. London: Department of Health.

Ekeland E, Heian F, Hagen KB, Abbott J, Nordheim L. 2004. Exercise to improve selfesteem in children and young people. Cochrane Database Syst Rev. 1:CD003683.

Haug E, Torsheim T, Sallis JF, Samdal O. 2010. The characteristics of the outdoor school environment associated with physical activity. Health Educ Res. 25:248-56

Leger LA, Mercier D, Gadoury C, Lambert J. 1988. The multistage 20 meter shuttle run test for aerobic fitness. J Sport Sci. 6:93-102.

NHS Information Centre. 2011. Health survey for England 2010. London: The Health and Social Care Information Centre.

Olds T, Tomkinson G, Leger L, Cazorla G. 2006. Worldwide variation in the performance of children and adolescents: An analysis of 109 studies of the 20-m shuttle run test in 37 countries. J Sport Sci. 24:1025-38.

Pretty J, Peacock J, Sellens M, Griffin M. 2005 The mental and physical health outcomes of green exercise. Int J Env Health Res. 15:319-37.

Pretty J, Peacock J, Hine R, Sellens M, South N, Griffin M. 2007. Green exercise in the UK countryside: effects on health and psychological well-being, and implications for policy and planning. Journal Env Plan Manage. 50:211-31. 
Ridgers ND, Stratton G, Fairclough SJ. 2004. Physical activity levels of children during school playtime. Sports Med. 36:359-71.

Ridgers ND, Stratton G, Fairclough SJ, Twisk JW. 2007a. Children's physical activity levels during school recess: A quasi-experimental intervention study. Int J Behav Nut Phys Act. $4: 1-9$

Ridgers ND, Stratton G, Fairclough SJ, Twisk JWR. 2007b. Long-term effects of a playground markings and physical structures on children's recess physical activity levels. Prev Med. 44:393-7.

Ridgers ND, Fairclough SJ, Stratton G. 2010. Twelve-month effects of a playground intervention on children's morning and lunchtime recess physical activity levels. J Phys Act Health.7:167-75.

Rosenberg M. 1965. Society and the adolescent self-image. Princeton: Princeton University Press; 1965.

Stratton G. 2000. Promoting children's physical activity in primary school: An intervention study using playground markings. Ergonomics. 43:1538-46.

Stratton G, Mullan E. 2005. The effect of multicolor playground markings on children's physical activity level during recess. Prev Med. 41:828-33.

Tandon P, Zhou C, Sallis J, Cain K, Frank L, Saelens B. 2012. Home environment relationships with children's physical activity, sedentary time, and screen time by socioeconomic status. Int J Behav Nutr Phys Act. 9:88. 
Treuth MS, Schmitz KH, Catellier DJ, McMurray RG, Murray DM, Almeida MJ, Going S, Norman JE, Pate R. 2004. Defining accelerometer thresholds for activity intensities in adolescent girls. Med Sci Sports Exerc. 36:1259-66.

Verstraete SJM, Cardon GM, De Clercq DLR, De Bourdeaudhuij IMM. 2006. Increasing children's physical activity levels during recess periods in elementary schools: The effects of providing game equipment. Eur J Public Health. 16:415-9.

Ward Thompson C, Aspinall P, Montarzino A. 2008. The childhood factor: Adult visits to green places and the significance of childhood experience. Env Behav. 40:111-43.

Wells N. 2000. At home with nature- Effects of "greenness" on children's cognitive functioning. Env Behav. 32:775-95.

Wells NM, Ashdown SP, Davies EHS, Cowett FD, Yang Y. 2007. Environment, design, and obesity. Opportunities for interdisciplinary collaborative research. Env Behav. 39:6-33.

Wood C, Angus C, Pretty J, Sandercock G, Barton J. 2012. A randomised control trial of physical activity in a perceived environment on self-esteem and mood in UK adolescents. Int J Env Health Res. 23:311-20. 
Tables

Table I. Descriptive statistics (mean \pm SD) for urban and rural school children.

\begin{tabular}{lllcccccc}
\hline & & Age $(\mathbf{y e a r s})$ & $\begin{array}{c}\text { Stature } \\
(\mathbf{c m})\end{array}$ & $\begin{array}{c}\text { Body mass } \\
(\mathbf{k g})\end{array}$ & $\begin{array}{c}\text { BMI } \\
\left(\mathbf{k g . m}^{-2}\right)\end{array}$ & $\begin{array}{c}\text { BMI } \\
(\mathbf{z} \text { Score })\end{array}$ & $\begin{array}{c}\mathbf{2 0 m S R T} \\
\left(\mathbf{k m . h}^{-\mathbf{1}}\right)\end{array}$ & $\begin{array}{c}\mathbf{2 0 m s r t} \\
(\mathbf{z}-\mathbf{s c o r e})\end{array}$ \\
\hline Urban & Male & $8.78 \pm 0.38$ & $1.30 \pm 0.07$ & $37.9 \pm 16.7$ & $22.5 \pm 9.8$ & $1.32 \pm 2.00$ & $10.5 \pm 1.0$ & $0.49 \pm 0.90$ \\
& Female & $8.58 \pm 0.26$ & $1.30 \pm 0.06$ & $38.6 \pm 12.1$ & $22.8 \pm 7.2$ & $1.86 \pm 1.26$ & $9.7 \pm 0.3$ & $0.25 \pm 0.30$ \\
& All & $8.73 \pm 0.36^{\mathrm{a}}$ & $1.30 \pm 0.06^{\mathrm{a}}$ & $38.1 \pm 15.5$ & $22.7 \pm 9.2^{\mathrm{a}}$ & $1.45 \pm 1.85^{\mathrm{a}}$ & $10.3 \pm 0.9$ & $0.43 \pm 0.80$ \\
\hline Rural & Male & $9.14 \pm 0.50$ & $1.39 \pm 0.07$ & $33.3 \pm 5.6$ & $17.3 \pm 2.3$ & $0.39 \pm 1.21$ & $10.4 \pm 0.9$ & $-0.63 \pm 3.09$ \\
& Female & $8.80 \pm 0.48$ & $1.35 \pm 0.08$ & $31.4 \pm 6.4$ & $17.1 \pm 2.1$ & $0.27 \pm 0.96$ & $9.6 \pm 0.4$ & $0.15 \pm 0.56$ \\
& All & $8.93 \pm 0.51$ & $1.37 \pm 0.08$ & $32.2 \pm 6.1$ & $17.2 \pm 2.1$ & $0.31 \pm 1.06$ & $9.9 \pm 0.7$ & $-0.18 \pm 2.05$ \\
\hline Total & Male & $8.91 \pm 0.45$ & $1.33 \pm 0.08$ & $36.2 \pm 13.7$ & $20.6 \pm 8.3$ & $1.00 \pm 1.81$ & $10.4 \pm 1.0$ & $0.10 \pm 2.00$ \\
& Female & $8.74 \pm 0.44^{\mathrm{b}}$ & $1.34 \pm 0.07$ & $33.5 \pm 8.8$ & $18.8 \pm 4.9$ & $0.72 \pm 1.27$ & $9.6 \pm 0.4^{\mathrm{b}}$ & $0.18 \pm 0.50$ \\
& All & $8.84 \pm 0.45$ & $1.33 \pm 0.08$ & $35.1 \pm 11.9$ & $19.8 \pm 7.1$ & $0.88 \pm 1.61$ & $10.1 \pm 0.9$ & $0.13 \pm 1.56$ \\
\hline
\end{tabular}

${ }^{\mathrm{a}}$ Indicates a significant difference from children in the rural school $(\mathrm{P}<0.05)$.

${ }^{\mathrm{b}}$ Indicates a significant sex differences for all children. 
Table II. Time spent in MVPA (mins) and self-esteem scores according to playtime activity and school environment (mean \pm SD).

\begin{tabular}{llcccc}
\hline & & \multicolumn{2}{c}{ Urban } & \multicolumn{2}{c}{ Rural } \\
\cline { 3 - 6 } & & MVPA (mins) & Self-esteem & MVPA (mins) & Self-esteem \\
\hline \multirow{2}{*}{ Sports } & Pre & $11.28 \pm 4.46$ & $21.60 \pm 7.69$ & $7.72 \pm 4.62$ & $19.05 \pm 6.29$ \\
& Post & $15.23 \pm 4.24$ & $18.89 \pm 6.10$ & $9.77 \pm 5.65$ & $18.36 \pm 5.98$ \\
& Total & $13.33 \pm 5.26$ & $19.89 \pm 7.49$ & $8.75 \pm 4.99$ & $18.52 \pm 5.86$ \\
\hline \multirow{2}{*}{ Orienteering } & Pre & $4.67 \pm 2.46$ & $18.00 \pm 6.24$ & $7.48 \pm 4.11$ & $16.82 \pm 6.15$ \\
& Post & $9.27 \pm 4.03$ & $15.67 \pm 6.73$ & $7.50 \pm 3.59$ & $16.27 \pm 5.19$ \\
& Total & $6.59 \pm 3.95$ & $17.00 \pm 6.43$ & $7.48 \pm 3.82$ & $16.29 \pm 5.45$ \\
\hline \multirow{2}{*}{ Total } & Pre & $7.93 \pm 5.14$ & $19.91 \pm 7.23$ & $7.63 \pm 4.25$ & $17.75 \pm 6.14$ \\
& Post & $12.60 \pm 5.44$ & $17.30 \pm 6.90$ & $8.58 \pm 4.65$ & $17.06 \pm 5.37$ \\
& Total & $10.07 \pm 5.75$ & $18.61 \pm 7.17$ & $8.11 \pm 4.46$ & $17.39 \pm 5.74$ \\
\hline
\end{tabular}

Note: A lower score $=$ a better self-esteem. 
Table III. Change in the time spent in MVPA (mins) due to the sports equipment and orienteering intervention in urban and rural school children (Mean \pm SD (95\% CI)).

\begin{tabular}{cccc}
\hline & Urban (mins) & Rural (mins) & Total (mins) \\
\hline Sports & $4.16 \pm 4.74(0.68-5.84)$ & $1.92 \pm 5.43(0.29-6.45)$ & $3.07 \pm 5.16(2.54-5.08)$ \\
Orienteering & $4.60 \pm 3.85(1.95-6.94)$ & $0.15 \pm 3.62(-1.71-1.37)$ & $2.15 \pm 4.31^{\mathrm{a}}(0.22-2.83)$ \\
Total & $4.36 \pm 4.31(3.69-6.35)$ & $1.00 \pm 4.6^{\mathrm{b}}(-0.97-1.59)$ & $2.62 \pm 4.75(1.44-3.48)$
\end{tabular}

${ }^{a}$ Indicates a significant difference between sports equipment and orienteering $(\mathrm{P}<0.001)$.

${ }^{\mathrm{b}}$ Indicates a significant difference between schools $(\mathrm{P}<0.05)$. 
Table IV. Change in self-esteem scores due to the sports equipment and orienteering intervention in urban and rural school children (Mean \pm SD $(95 \% \mathrm{CI})$ ).

\begin{tabular}{cccc}
\hline & Urban & Rural & Total \\
\hline Sports & $2.33 \pm 6.69(-0.65-3.66)$ & $0.78 \pm 5.18(-1.68-2.46)$ & $1.53 \pm 5.94(-0.51-2.41)$ \\
Orienteering & $2.16 \pm 5.81(0.68-5.16)$ & $0.59 \pm 3.33(-0.97-3.19)$ & $1.32 \pm 4.66(0.51-3.51)$ \\
Total & $2.25 \pm 6.21(0.63-3.79)$ & $0.68 \pm 4.31(-0.75-2.25)$ & $1.43 \pm 5.32(0.24-2.48)$ \\
\hline
\end{tabular}

Note: A positive change $=$ an improvement self-esteem. 